Article

\title{
Examining the Factors that Affect the Preparation of Life after Retirement and Quality of Life of South Korean Adults across Different Age Groups
}

\author{
Mi-Lyang Kim ${ }^{1}{ }^{(\mathbb{C}}$, Young-Han Lee ${ }^{2} \mathbb{D}$ and Seo-Youn Hong ${ }^{1, *}$ \\ 1 Department of Sport, Leisure, \& Recreation, Soonchunhyang University, Asan 31538, Korea; mlkim@sch.ac.kr \\ 2 Department of Kinesiology, Sport Studies, Mississippi State University, Mississippi State, MS 39762, USA; \\ y1690@msstate.edu \\ * Correspondence: ghdhsy0617@sch.ac.kr
}

Citation: Kim, M.-L.; Lee, Y.-H.; Hong, S.-Y. Examining the Factors that Affect the Preparation of Life after Retirement and Quality of Life of South Korean Adults across Different Age Groups. Sustainability 2021, 13, 5351. https://doi.org/ $10.3390 /$ su13105351

Academic Editor: Gabriela Topa

Received: 30 March 2021

Accepted: 7 May 2021

Published: 11 May 2021

Publisher's Note: MDPI stays neutral with regard to jurisdictional claims in published maps and institutional affiliations.

Copyright: (C) 2021 by the authors. Licensee MDPI, Basel, Switzerland. This article is an open access article distributed under the terms and conditions of the Creative Commons Attribution (CC BY) license (https:/ / creativecommons.org/licenses/by/ $4.0 /)$.

\begin{abstract}
The aim of the current study is twofold. First, a preliminary analysis was conducted to discover the important factors in terms of preparing for life after retirement across different South Korean age groups (i.e., the 30s, 40s, and 50s). In this process, the level of importance and the statistical significance of the group difference were confirmed based on the ANOVA results. Second, a stepwise regression technique was utilized, as the main analysis, to explore the association between the preparation for life after retirement factors and perceived quality of life. One-way ANOVA analysis results indicated that there were significant differences between age groups in terms of leisure activities, psychological health, physical health, and emotional health factors $(p<0.001)$. No difference in factors pertaining to family relationships, finances, and social relationships was observed. Furthermore, the stepwise regression analysis results entail that financial stability and psychological health proved to be the most dominant factors associated with quality of life regardless of age. While the family relationship was an important factor for the 40s group, the 50s group perceived emotional health as an important factor that relates to their quality of life. In essence, it is important to provide educational programs and materials that are readily accessible to individuals preparing for retirement to promote successful preparation toward retirement and improving quality of life.
\end{abstract}

Keywords: aging population; life after retirement; retirement preparation; quality of life

\section{Introduction}

International organizations such as the United Nations (UN) and the Organisation for Economic Co-operation and Development (OECD) are shifting the paradigm for social development from centering on one's GDP to one's "quality of life". Everyone desires a happy and successful life, and proper and timely preparation for life after retirement is a necessary component $[1,2]$. South Korea is a representative country of the two international organizations that is rapidly moving toward an aging society; thus, introducing measures to help enable life after retirement preparation is crucial to mitigate elderly tribulations [3,4].

Given that aging is unavoidable, preparation for it should be based on the population's predicted life span [5]. Previously, preparation for life after retirement was constructed and studied solely in terms of financial preparation [6]. However, in recent years, preparation for life after retirement has evolved into a life-long process that incorporates factors other than financial preparation [5], and many prior studies suggest that preparation requires a comprehensive and multidimensional realm [4-10]. The importance of balanced preparation of each multidimensional element needed for senior citizens is further conveyed by Part, Fung, Rothermund, and Hess [11], in which study results indicated that multiple factors such as perceived control and future-self views influenced preparing for old age, highlighting the importance of diversity and culture. 
To live a happy and successful life after retirement, it is important to be aware of and to prepare for a variety of factors from an early age. Life events that individuals experience internally and externally influence each other within one's life cycle, develop through age-changing stages, and continue to form unique perceptions. This can be explained by a "Continuity Theory" [12,13], whereby people intend to conserve and maintain internal and external traits and structures throughout their lifetime [13]. With aging, the motivation to preserve current resources, especially in times of hardship, rather than making efforts to secure new resources increases [14,15]. Preparing for a happier, better quality of life needs to be initiated at an early age to reap the maximum benefit during the aging process. However, despite the importance of these preparations, studies on the factors that affect preparing for life after retirement are insufficient. In particular, age- and time-related variables have an influence on life after retirement preparation [11], and several surveys have been completed by those who are about to retire (e.g., middle-aged adults) and by the newly retired [16] are important topics for further investigation.

Meanwhile, sufficiently preparing for life after retirement is correlated with quality of life characteristics [17] and allows for a greater sense of ease and joy [18-20]. Several studies have reported that preparation for life after retirement has many benefits, not only physically $[17,21]$ but also psychologically. Recent studies reflect this point of view and show that preparation for life after retirement begins as early as one's 30s. A comparative study by age group reveals that there are differences in multidimensional preparation factors according to age $[5,6,22]$. Specifically, Hershey et al. [22] state that although the average age of the study participants was only 36.1 years old, they would have preferred to have started their preparation for life after retirement even earlier. A study by Kornadt and Rothermund [5] reports that there is a distinct difference in the factors of preparation for life after retirement amongst a group of people whose loss of work role and its substitution with leisure activities are relevant and those in which the deterioration of one's health, dependence/independence, generativity issues, and closeness to death might become more important. It also suggests that the characteristics of preparation, most notably the psychological parameters, differ due to cultural differences among eastern and western countries.

Among East Asian countries, South Korea represents a common, rapid trend toward moving to a super-aged society. South Korea established "The Age Preparation Support Act", which defines preparation for life after retirement as a proactive response to disease, neglect, and solitude that may occur as citizens age. This definition of preparation for life after retirement is focused on preparing for economic and physiological stability, but not on psychological and emotional sustenance. Additionally, the aging self-diagnosis measure used by the Ministry of Health and Welfare in South Korea is subjective by nature and lacks diversity, as it consists of financial security (14 questions), physical health (11 questions), leisure activities (five questions), and social relationships (nine questions). Most importantly, there were no inquiries about preparing for life after retirement related to psychological and emotional variables, which are viewed as increasingly paramount for enancing the quality of life as one continues to age.

In addition to the aforesaid statements is that South Korea's Better Life Index (BLI), which measures the "cognitive social network", one of the life quality factors ranks 36th, the lowest among OECD countries. Meanwhile, quality of life refers to the self-satisfaction of major life events and subjective perceptions of happiness and overall satisfaction [23]. This quality of life is evaluated in terms of multi-level dimensions as a general and abstract concept [24]. Lee [25] noted that better preparation for life after retirement was directly proportional to a better quality of life. Kim, Jung, and Lee [26] also concluded that economical and psychological preparations lead to a feeling of experiencing a better, more successful life, and to higher quality of life. Recently, Hong and Kim [27] developed a universal preparation for life after retirement measure consisting of seven factors: family relationships, social relationships, physical health, psychological health, emotional health, leisure activities, and financial security. 
Despite the noble effort from previous studies, no studies to date have examined the multidimensional factors affecting life after retirement that play critical roles in one's quality of life across different age groups. Studies that have explored the comprehensive measures of preparing for life after retirement and provide strategies to employ such measures are also lacking. The aim of the current study, therefore, is to discover the primary factors associated with preparation of life after retirement and further explore how each factor contributes to enhancing the quality of life for South Koreans across different age groups.

The current study, based on empirical results, presents alternative measures and future directions in terms of preparing for life after retirement. It also observes primary factors that affect the quality of life across different age groups and introduces policy directions to improve the quality of life for South Korean senior citizens. The research implications may further help understand the full spectrum of life after retirement preparation and its influence on the quality of life in general.

\section{Materials and Methods}

\subsection{Participants}

Subjects consisting of 350 adults aged from thirty to fifty residing in large-, middle-, and small-sized cities in South Korea participated in the survey. The respondents were proportionally sampled per gender, age, and region. Seventeen surveys were excluded due to incomplete responses. A total of 333 data were further analyzed. The respondents' demographics are shown in Table 1 . The survey procedure was ethically approved by Chung-Ang University (1041078-202102-HRSB-045-01).

Table 1. Characteristics of the participants.

\begin{tabular}{cccc}
\hline Factor & & $\mathbf{N}$ & \% \\
\hline \multirow{2}{*}{ Gender } & Male & 166 & 49.8 \\
& Female & 167 & 50.2 \\
\hline \multirow{2}{*}{ Age } & $30-39$ & 108 & 32.4 \\
& $40-49$ & 112 & 33.6 \\
& $50-59$ & 113 & 33.9 \\
\hline \multirow{2}{*}{ Region } & Large-sized city & 108 & 32.4 \\
& Mid-sized city & 112 & 33.6 \\
& Small-sized city & 113 & 33.9 \\
\hline \multirow{3}{*}{ Education } & Middle school & 1 & 0.3 \\
& High school & 56 & $16.8 \%$ \\
& College & 230 & $69.1 \%$ \\
& Graduate school & 46 & $13.8 \%$ \\
\hline \multirow{2}{*}{ Income } & Less than US \$1000 & 21 & $6.3 \%$ \\
per month (US \$) & US \$1000-US \$2000 & 37 & $11.1 \%$ \\
& US \$2000-US \$3000 & 92 & $27.6 \%$ \\
& US \$3000-US \$4000 & 80 & $24.0 \%$ \\
& US \$4000-US \$5000 & 48 & $14.4 \%$ \\
& US \$5000 or more & 55 & $16.5 \%$ \\
\hline
\end{tabular}

\subsection{Measures}

To secure structural validity of the scales, confirmatory factor analysis was applied. Regarding factor analysis, the coefficient value of the factor lower than 0.40 was deleted. Reliability tests of the finalized scales were confirmed with Cronbach's $\alpha$ coefficients. In addition, a stepwise regression analysis was applied for the main analysis. The specific composition of the questionnaire and the results of the factor analysis are as follows. 


\subsubsection{The Scale of Universal Preparation for Life after Retirement}

To measure the level of preparation for life after the retirement of the respondents, a questionnaire-style survey was utilized. The participants were asked to fill out a selfadministered survey that consisted of multiple items related to the scale. The participants were further instructed to select the appropriate option for each item and furnish the details as required in respective questions to enable the correct assessment of the scale.

Specifically, Hong and Kim's [27] Scale of Universal Preparation for life after retirement was utilized. The scale consisted of seven factors: family relationships (4 questions), social relationships (4 questions), physical health (4 questions), psychological health (4 questions), emotional health (4 questions), leisure activity (4 questions), and financial (4 questions). The survey was constructed on a 5-point Likert scale including items such as "I feel that my family members are harmonious", "I have a leisure activity I periodically participate in", "I have sufficient financial resources to support my leisure activity", and "I can easily endure and overcome solitude and loneliness" (see Table 2 for details). The scores ranged from 28 to 140 points. A high score indicated a high level of readiness in terms of preparation for life after retirement, while a low score indicated a low level of readiness.

To test the structural validity of the scale, a confirmatory factor analysis (CFA) was performed. Bentler [28] and Hu and Bentler's [29] "goodness of fit" indices, commonly used to decide the goodness of fit of a model, $\chi^{2} / \mathrm{df}, \mathrm{CFI}, \mathrm{TLI}$, and RMSEA values were employed. The confirmatory factor analysis using 28 questions of 7 factors revealed $\chi^{2} / \mathrm{df}$ $=835.447 / 329, \mathrm{CFI}=0.904, \mathrm{TLI}=0.890$, and RMSEA $=0.068$. The levels of standardized $\beta$ values (all the $\beta$ values were 0.572 or above, and the significance of those $\beta$ values (where $p<0.01$ ) were in proper levels, and all AVE values were 0.573 or above; the convergent validity of the model was secured.

To prove the reliability of the model and convergent/discriminant validities of the model, composition reliability (CR) and average variance extracted (AVE) were calculated. The results are shown in Table 2. According to Fornell and Larcker (1981), if CR is 0.7 or above, and AVE is 0.5 or above, measurement questions are considered to be reliable. If AVE is higher than the squared multiple correlations (SMC) among factors, validity among factors is secured. The data analysis showed that the range of CRs was between 0.842 and 0.939 , and higher than 0.7; the range of AVEs was between 0.573 and 0.793 , and higher than 0.5 ; the range of SMCs was between 0.045 and 0.596, and lower than the AVEs. Thus, the reliability and convergent/discriminant validities of the model were secured. The results of the confirmatory factor analysis are shown in Table 2. 
Table 2. Results of the confirmatory factor analysis of the preparation for life after retirement scale.

\begin{tabular}{|c|c|c|c|c|c|}
\hline Factor & Contents & B & S.E. & C.R. & AVE \\
\hline \multirow{4}{*}{$\begin{array}{l}\text { Family } \\
\text { relationship }\end{array}$} & I feel that my family members are harmonious & 0.825 & 0.185 & \multirow{4}{*}{0.939} & \multirow{4}{*}{0.793} \\
\hline & I am interested in my family members & 0.805 & 0.29 & & \\
\hline & I talk to my family members frequently & 0.906 & 0.115 & & \\
\hline & I feel that our family members trust and depend on each other & 0.86 & 0.162 & & \\
\hline \multirow{4}{*}{$\begin{array}{l}\text { Leisure } \\
\text { activity }\end{array}$} & I have a leisure activity I periodically participate in & 0.905 & 0.169 & \multirow{4}{*}{0.912} & \multirow{4}{*}{0.725} \\
\hline & I make efforts to keep participating in the leisure activity & 0.929 & 0.123 & & \\
\hline & I make efforts to learn more, if necessary, in my leisure activity & 0.765 & 0.335 & & \\
\hline & $\begin{array}{c}\text { I have knowledge and expertise of a high level on the leisure } \\
\text { activity I participate in }\end{array}$ & 0.672 & 0.403 & & \\
\hline \multirow{4}{*}{ Finances } & $\begin{array}{l}\text { I have sufficient financial resources to support my } \\
\text { leisure activity }\end{array}$ & 0.767 & 0.326 & \multirow{4}{*}{0.842} & \multirow{4}{*}{0.573} \\
\hline & $\begin{array}{l}\text { I have sufficient financial resources to spend on family travel or } \\
\text { family event }\end{array}$ & 0.796 & 0.314 & & \\
\hline & I have sufficient financial resources to live independently & 0.64 & 0.451 & & \\
\hline & I am economically prepared to support my future life & 0.673 & 0.46 & & \\
\hline \multirow{4}{*}{$\begin{array}{l}\text { Social } \\
\text { relationship }\end{array}$} & I have friends whom I can depend on if I am needy & 0.8 & 0.295 & \multirow{4}{*}{0.899} & \multirow{4}{*}{0.693} \\
\hline & I have friends with whom I can talk frankly & 0.651 & 0.267 & & \\
\hline & I have close friends I frequently meet & 0.73 & 0.342 & & \\
\hline & I get along harmoniously with people around me & 0.897 & 0.159 & & \\
\hline \multirow{4}{*}{$\begin{array}{l}\text { Psychological } \\
\text { health }\end{array}$} & I tend to think positively of everything & 0.748 & 0.303 & \multirow{4}{*}{0.884} & \multirow{4}{*}{0.656} \\
\hline & I make efforts to maintain a peaceful mind & 0.719 & 0.264 & & \\
\hline & $\begin{array}{l}\text { Even if I get hurt by someone, I do not harbor it long in } \\
\text { my heart }\end{array}$ & 0.746 & 0.344 & & \\
\hline & I am a valuable being in the world. & 0.779 & 0.261 & & \\
\hline \multirow{4}{*}{$\begin{array}{l}\text { Physical } \\
\text { health }\end{array}$} & I make efforts to stay in shape in various ways & 0.745 & 0.4 & \multirow{4}{*}{0.859} & \multirow{4}{*}{0.605} \\
\hline & I regularly exercise to keep in shape & 0.786 & 0.247 & & \\
\hline & I have no physical problem moving my body and lead a life & 0.642 & 0.404 & & \\
\hline & I lead an orderly life & 0.695 & 0.299 & & \\
\hline \multirow{4}{*}{$\begin{array}{l}\text { Emotional } \\
\text { health }\end{array}$} & I am ready to embrace my death & 0.742 & 0.27 & \multirow{4}{*}{0.879} & \multirow{4}{*}{0.649} \\
\hline & I easily accept my changing appearance with age & 0.572 & 0.438 & & \\
\hline & I adjust myself to changes in my life & 0.742 & 0.246 & & \\
\hline & I can easily endure and overcome solitude and loneliness & 0.812 & 0.176 & & \\
\hline
\end{tabular}

\subsubsection{Quality of Life Scale}

To test the structural validity of the questionnaire, confirmatory factor analysis was conducted, as developed by Fischer and Corcoran [30]. It was designed to measure quality of life that includes the perspective of the overall life satisfaction. It consisted of 5 statements: 'I lead a life that is close to an ideal life', 'my life conditions are very good', 'I am satisfied with my life', 'I have achieved whatever I want from my life', and 'if I were given one more chance to live, I would like to repeat my current life'. Respondents were asked to designate their choices on the 5-point Likert scale. The scores ranged from 5 to 25 points. A high score indicated a high quality of life, while a low score indicated a low quality of life. The reliability of the scale was confirmed by Cronbach's $\alpha=0.897$. The confirmatory factor analysis results indicated a good model fit $\left(\chi^{2} / \mathrm{df}=10.025 / 4=2.506, \mathrm{CFI}=0.988\right.$, $\mathrm{TLI}=0.984$, RMSEA $=0.067$ ) according to the threshold proposed by Bentler [28] and $\mathrm{Hu}$ and Bentler [29]. The standardized $\beta$ and the AVE values confirmed reliability and convergent/discriminant validities. The detailed findings of the confirmatory factor analysis of the scale are shown in Table 3. 
Table 3. Results of confirmatory factor analysis of quality of life.

\begin{tabular}{|c|c|c|c|c|c|}
\hline Factor & Contents & B & S.E. & C.R. & AVE \\
\hline \multirow{5}{*}{ Quality of Life } & I am satisfied with my life & 0.737 & 0.043 & \multirow{5}{*}{0.727} & \multirow{5}{*}{0.683} \\
\hline & I have achieved whatever I want from my life & 0.829 & 0.042 & & \\
\hline & My life conditions are very good & 0.854 & 0.041 & & \\
\hline & $\begin{array}{l}\text { If I were given one more chance to live, I } \\
\text { would like to repeat my current life }\end{array}$ & 0.847 & 0.043 & & \\
\hline & I lead a life that is close to an ideal life & 0.757 & 0.049 & & \\
\hline \multicolumn{6}{|c|}{ Model Fit Indices: $\chi^{2} / \mathrm{df}=10.025 / 4=2.506, \mathrm{CFI}=0.988, \mathrm{TLI}=0.984, \mathrm{RMSEA}=0.067$} \\
\hline
\end{tabular}

\subsection{Main Analysis}

The survey data were analyzed using SPSS 25.0 and AMOS 23.0 programs. Descriptive statistics were acquired. In terms of the main analysis, stepwise regression analysis was used to examine how preparation for life after retirement affects different age groups' perceived quality of life. In stepwise regression, the choice of predictive variables is carried out by an automatic procedure, not by the researcher. In other words, the selection and order of which variables to be analyzed are automatically determined based on the correlation coefficient [31]. When multiple variables are uploaded in the multiple regression analysis, stepwise regression analysis is superior to the other methods [31]. In testing our hypotheses, the statistical significance level was set at $\alpha=0.05$. Furthermore, to identify criterion-related validity, directionality, and relativity of variables, Pearson's correlation coefficients were acquired.

\section{Results}

\subsection{Correlation Analysis}

As there was no correlation coefficient higher than 0.80 between factors, multicollinearity was not an issue. Additionally, all variables were significantly correlated. Correlation coefficients among variables are shown in Table 4.

Table 4. Correlation matrix for all measurement variables.

\begin{tabular}{|c|c|c|c|c|c|c|c|c|}
\hline & $\begin{array}{l}\text { Family } \\
\text { Relation- } \\
\text { ships }\end{array}$ & $\begin{array}{l}\text { Leisure } \\
\text { Activity }\end{array}$ & Finances & $\begin{array}{l}\text { Social } \\
\text { Relation- } \\
\text { ships }\end{array}$ & $\begin{array}{l}\text { Psychological } \\
\text { Health }\end{array}$ & $\begin{array}{c}\text { Physical } \\
\text { Health }\end{array}$ & $\begin{array}{l}\text { Emotional } \\
\text { Health }\end{array}$ & $\begin{array}{l}\text { Quailty } \\
\text { of Life }\end{array}$ \\
\hline Family relationship & 1 & & & & & & & \\
\hline Leisure activity & $0.238 * *$ & 1 & & & & & & \\
\hline Finances & $0.446^{* *}$ & $0.418 * *$ & 1 & & & & & \\
\hline Social relationship & $0.388^{* *}$ & 0.370 ** & $0.404 * *$ & 1 & & & & \\
\hline Psychological health & $0.376^{* *}$ & 0.606 ** & $0.460 * *$ & $0.436 * *$ & 1 & & & \\
\hline Physical health & $0.305^{* *}$ & $0.521 * *$ & $0.449^{* *}$ & $0.289 * *$ & $0.496 * *$ & 1 & & \\
\hline Emotional health & $0.277^{* *}$ & $0.341^{* *}$ & $0.371^{* *}$ & $0.215^{* *}$ & $0.477^{* *}$ & $0.318^{* *}$ & 1 & \\
\hline Quality of Life & $0.429 * *$ & 0.433 ** & $0.621 * *$ & $0.344 * *$ & $0.557^{* *}$ & $0.425^{* *}$ & 0.416 ** & 1 \\
\hline
\end{tabular}

\subsection{Difference in Factors Affecting Preparation for Life after Retirement across Different Age Groups}

This research examined the factors affecting preparation for life after retirement across three different age groups (i.e., the 30s, 40s, and 50s). It was found that there were significant differences in leisure activities, psychological health, physical health, and emotional health $(p<0.001)$. No difference in factors of family relationships, finances, and social relationships was observed. Hence, the factors with no significant difference were omitted, and only the 
ones with statistical significance were included in the main analysis. Additionally, post-hoc tests of Tukey showed that there were greater differences among survey subjects in their 50s than among those in their 30s and 40s. The findings are shown in Table 5.

Table 5. One-way ANOVA analysis for preparation for life after retirement across different age groups.

\begin{tabular}{|c|c|c|c|c|c|c|}
\hline Variable & & $\mathbf{M}$ & SD & $F$ & $p$ & Tukey HSD \\
\hline \multirow{3}{*}{$\begin{array}{l}\text { Family } \\
\text { relationship }\end{array}$} & $30-39$ & 3.82 & 0.73 & \multirow{3}{*}{2.662} & \multirow{3}{*}{0.071} & \\
\hline & $40-49$ & 3.65 & 0.79 & & & \\
\hline & $50-59$ & 3.86 & 0.62 & & & \\
\hline \multirow{3}{*}{ Leisure activity } & $30-39$ & 3.05 & 0.85 & \multirow{3}{*}{4.043} & \multirow{3}{*}{0.017} & \multirow{3}{*}{$30,40<50$} \\
\hline & $40-49$ & 2.94 & 0.78 & & & \\
\hline & $50-59$ & 3.23 & 0.74 & & & \\
\hline \multirow{3}{*}{ Finances } & $30-39$ & 3.18 & 0.72 & \multirow{3}{*}{1.250} & \multirow{3}{*}{0.288} & \\
\hline & $40-49$ & 3.03 & 0.82 & & & \\
\hline & $50-59$ & 3.14 & 0.71 & & & \\
\hline \multirow{3}{*}{$\begin{array}{l}\text { Social } \\
\text { relationship }\end{array}$} & $30-39$ & 3.72 & 0.74 & \multirow{3}{*}{2.249} & \multirow{3}{*}{0.107} & \\
\hline & $40-49$ & 3.53 & 0.699 & & & \\
\hline & $50-59$ & 3.57 & 0.64 & & & \\
\hline \multirow{3}{*}{ Psychological health } & $30-39$ & 3.35 & 0.72 & \multirow{3}{*}{3.275} & \multirow{3}{*}{0.039} & \multirow{3}{*}{$30,40<50$} \\
\hline & $40-49$ & 3.40 & 0.62 & & & \\
\hline & $50-59$ & 3.57 & 0.63 & & & \\
\hline \multirow{3}{*}{ Physical health } & $30-39$ & 3.35 & 0.69 & \multirow{3}{*}{10.872} & \multirow{3}{*}{$<0.001$} & \multirow{3}{*}{$30,40<50$} \\
\hline & $40-49$ & 3.36 & 0.65 & & & \\
\hline & $50-59$ & 3.70 & 0.55 & & & \\
\hline \multirow{3}{*}{ Emotional health } & $30-39$ & 3.21 & 0.61 & \multirow{3}{*}{4.961} & \multirow{3}{*}{0.008} & \multirow{3}{*}{$30,40<50$} \\
\hline & $40-49$ & 3.29 & 0.63 & & & \\
\hline & 50-59 & 3.47 & 0.64 & & & \\
\hline
\end{tabular}

\subsection{Logistic Regression Analysis}

3.3.1. Preparation for Life after Retirement Factors Affecting the Quality of Life (Group 30s)

To analyze preparation for life after retirement factors affecting life quality among those in the 30s, a stepwise regression analysis was performed. In Model 1, finances alone composed $37.4 \%$ of life quality $(F(1,106)=63.460, p=0.001)$. In Model 2 , finances and psychological health were combined; the explanatory power rose to $44.5 \%(F(2,105)=42.015$, $p=0.001$ ). Family relationships, social relationships, physical health, psychological health, and leisure activities were excluded from the model due to statistical insignificance. The findings are shown in Table 6.

Table 6. Stepwise regression analysis for quality of life (group 30s).

\begin{tabular}{ccccccc}
\hline & & \multicolumn{5}{c}{ Quality of Life } \\
\cline { 3 - 6 } & & $\mathbf{R}^{\mathbf{2}}$ & $\mathbf{B}$ & S.E. & Beta & $\mathbf{t}$ \\
\hline \multirow{2}{*}{1} & (constant) & & 0.760 & 0.278 & & $2.731^{* *}$ \\
& Finances & 0.374 & 0.678 & 0.085 & 0.612 & $7.966^{* * *}$ \\
\hline \multirow{2}{*}{2} & (constant) & & 0.157 & 0.311 & & 0.503 \\
& Finances & & 0.516 & 0.092 & 0.466 & $5.613^{* * *}$ \\
& Psychological health & 0.445 & 0.333 & 0.092 & 0.302 & $3.639^{* * *}$ \\
\hline
\end{tabular}

${ }^{* *} p<0.01,{ }^{* * *} p<0.001$.


3.3.2. Preparation for Life after Retirement Factors Affecting the Quality of Life (Group 40s)

To analyze preparation for life after retirement factors affecting life quality among those in the 40s, a stepwise regression analysis was used. In Model 1, the finances factor explained $55.3 \%$ of life quality $(F(1,110)=136.223, p=0.001)$. In Model 2 , finances and family relationships combined had an explanatory power that rose to $62.5 \%(F(2,109)=90.834$, $p=0.001)$. In Model 3, finances, family relationships, and psychological health had a combined explanatory power of $64.8 \%(F(3,108)=66.249, p=0.001)$. However, social relationships, physical health, psychological health, and leisure activities were excluded from the model due to statistical insignificance. The findings are shown in Table 7.

Table 7. Stepwise regression analysis for quality of life (group 40s).

\begin{tabular}{|c|c|c|c|c|c|c|}
\hline & & \multicolumn{5}{|c|}{ Quality of Life } \\
\hline & & $\mathbf{R}^{2}$ & B & S.E. & Beta & $\mathbf{t}$ \\
\hline \multirow[b]{2}{*}{1} & (constant) & & 0.633 & 0.200 & & $3.168^{* *}$ \\
\hline & Finances & 0.553 & 0.743 & 0.064 & 0.744 & $11.671^{* * *}$ \\
\hline \multirow{3}{*}{2} & (constant) & & -0.066 & 0.239 & & -0.274 \\
\hline & Finances & & 0.586 & 0.068 & 0.587 & $8.622^{* * *}$ \\
\hline & Family relationship & 0.625 & 0.321 & 0.070 & 0.311 & $4.567^{* * *}$ \\
\hline \multirow{4}{*}{3} & (constant) & & -0.477 & 0.280 & & -1.705 \\
\hline & Finances & & 0.512 & 0.072 & 0.513 & $7.152^{* * *}$ \\
\hline & Family relationship & & 0.267 & 0.071 & 0.259 & $3.745^{* * *}$ \\
\hline & Psychological health & 0.648 & 0.244 & 0.092 & 0.187 & $2.651^{* * *}$ \\
\hline
\end{tabular}

3.3.3. Preparation for Life after Retirement Factors Affecting the Quality of Life (Group 50s)

To analyze preparation for life after retirement affecting life quality among those in the 50s, a stepwise regression analysis was used. In Model 1, psychological health composed $31.8 \%$ of the quality of life $(F(1,111)=51.760, p=0.001)$. In Model 2 , the psychological health and finances enhanced the quality of life to $39.8 \%(F(2,110)=36.339, p=0.001)$. In Model 3, the psychological health, finances, and emotional health increased the quality of life to $42.4 \% \%(F(3,109)=26.775, p=0.001)$. However, family relationships, social relationships, physical health, and leisure activities were excluded from the model due to statistical insignificance. The findings are shown in Table 8.

Table 8. Stepwise regression analysis for quality of life (group 50s).

\begin{tabular}{|c|c|c|c|c|c|c|}
\hline & & \multicolumn{5}{|c|}{ Quality of Life } \\
\hline & & $\mathbf{R}^{2}$ & B & S.E. & Beta & $\mathbf{t}$ \\
\hline \multirow{2}{*}{1} & (constant) & & 0.726 & 0.321 & & $2.264 *$ \\
\hline & Psychological health & 0.318 & 0.637 & 0.088 & 0.564 & $7.194^{* * *}$ \\
\hline \multirow{3}{*}{2} & (constant) & & 0.233 & 0.329 & & 0.708 \\
\hline & Psychological health & & 0.506 & 0.090 & 0.448 & $5.604^{* * *}$ \\
\hline & Finances & 0.398 & 0.306 & 0.080 & 0.305 & $3.819^{* * *}$ \\
\hline \multirow{4}{*}{3} & (constant) & & -0.084 & 0.353 & & -0.237 \\
\hline & Psychological health & & 0.413 & 0.098 & 0.366 & $4.224^{* * *}$ \\
\hline & Finances & & 0.282 & 0.079 & 0.282 & $3.555^{* * *}$ \\
\hline & Emotional health & 0.424 & 0.208 & 0.093 & 0.188 & 2.237 \\
\hline
\end{tabular}

$* p<0.05,{ }^{* * *} p<0.001$. 


\section{Discussion}

The purpose of this study was to analyze how preparation after retirement affects the quality of life across different age groups (i.e., the 30s, 40s, and 50s). We concluded that factors South Korean adults incorporated for preparation of life after retirement varied by age. Specifically, leisure activities, psychological health, physical health, and emotional health were statistically significant, and the difference in preparation for life after retirement was higher in one's fifties than in one's thirties and forties. However, there were no significant differences in family relationships, social relationships, and finances. A study by Kornadt and Rothermund [5] also compared how life after retirement preparation factors differed according to age. Their German subjects were aged thirty to eighty, and their life after retirement preparation was categorized into different groups based on the stage in their life cycles in which the subjects in the relatively earlier stage prepared for activities, leisure, work, fitness, and appearance and those in the latter part of the life cycle prepared for emergencies, dependence/independence, housing, and financial arrangements. The current study supported the previous study results by suggesting that the factors that affect preparation for life after retirement vary across different age groups [5].

Furthermore, it seems that South Korean individuals in their fifties begin to perceive that preparing for life after retirement is an important issue. The study results further suggest that leisure activity, psychological health, physical health, and emotional health are important factors that affect the quality of life of individuals in their thirties [22]. It is vital to recognize the necessity of this preparation and establish plans to secure it. In particular, leisure activities should commence from the thirties to be sustained and physically built upon so that one might engage in them without difficulty as one continues to age [32]. In this sense, active participation in leisure activities may positively influence physical, psychological, and emotional health [33].

Second, finances and psychological health were found to be factors for life after retirement preparation that affected the quality of life of all age groups examined in this study. In particular, subjects in their thirties and forties deemed that finances were most important, followed by psychological health. Those in their fifties stated the opposite; psychological health was placed first, followed by finances. A completely different perception and practice of preparation for life after retirement in the 50s retirement population suggested that the age at which this pattern occurred yielded a distinct difference in focus and needs from that of the younger age group. In particular, emotional health, which did not affect younger age groups, was important to prepare for elderly life and psychological and emotional health for those in their fifties.

Psychological and emotional health were important indexes in understanding the preparation for life after retirement beyond objective indicators such as income [34,35]. The psychological and emotional health questions used in this study were related to the psychological and emotional control and adjustment of an individual's life. Many previous studies have shown that psychological regulation was essential for enhancing the quality of life and was an important factor in successful aging [36,37]. It has been shown that perceived control was positively correlated with life satisfaction as part of the quality of life domain during life after the retirement age $[9,17,19]$. Therefore, South Korean adults in their fifties should focus on psychological and emotional health in preparation for life after retirement to improve their quality of life. It was necessary to find a direction in which entry into senior citizenship could be achieved in a psychologically and emotionally stable state.

Third, subjects in their thirties and forties stated that finances were the most important factor for preparation for life after retirement in terms of positively affecting one's quality of life. As shown in Table 5, family and social relationships were highly valued in the thirties and fifties age groups, and financial security and leisure activity participation had a low influence. These results supported previous research findings that preparation in the financial sector is positively related to preparation for life after retirement [38-40]. Additionally, the lack of financial preparation may indicate poor emotional health, since 
this factor was identified to affect psychological health, which indicates that it needs to be prepared at a relatively earlier age [41]. This suggests that it may be necessary to introduce an education system geared toward financial preparation and economic coping measures for each age group up, based on a prolonged life span. This is especially true for life events that take place in one's thirties and forties. There is a need for active interest from both local and federal government levels that should be viewed as essential rather than as a mere option.

Fourth, the significance of family relationships appeared only in one's forties. This entails that family is perhaps the most important factor in one's forties. This phenomenon is understandable considering that South Korea is known to emphasize the importance of collective values and family relations $[42,43]$ and is a country that values marital relationships centered around children [42,43]; it is in one's forties that generally a family is formed around children. Therefore, focusing on family relationships in this particular age group may improve quality of life as one prepares for life after retirement, especially entering into the older age group.

\section{Conclusions}

The findings from the analysis suggest that South Korean adults' preparation for life after retirement had three distinct patterns. First, South Korean adults tend to focus on specific factors related to preparation for life after retirement. Second, a common factor (i.e., finances) that South Korean adults regarded as important in preparing for life after retirement according to ages between 30 and 40 was found. Third, South Korean adults recognized the importance of preparation for life after retirement in their fifties, and the factors of that preparation recognized as important are significantly different from that of their thirties and forties.

In future studies, it will be necessary to expand the age ranges and examine the pattern that affects the preparation of life after retirement as they relate to one's quality of life. Additionally, other factors (i.e., leisure activities, social relationships, physical health) that influence preparation for life after retirement may vary in importance at different ages. On a related note, it may be worth investigating intergenerational transfers. That is, checking whether pensioners use their children's help and to what extent may help understand how sharing resources between family members affect preparing for life after retirement. As such, examining more diverse patterns of preparation for life after retirement would further contribute to the body of knowledge. It would also be meaningful to develop a model for preparation for life after retirement that would improve the quality of life according to the individual's life cycle. Most importantly, it is paramount to test and develop a preparation for life after retirement model across different cultures and subjects to seek out a general understanding of how the model may further affect the quality of life.

Author Contributions: Conceptualization, S.-Y.H. and M.-L.K.; methodology, M.-L.K.; software, S.-Y.H.; validation, M.-L.K. and Y.-H.L.; formal analysis, M.-L.K.; investigation, M.-L.K.; resources, M.-L.K.; data curation, S.-Y.H.; writing—original draft preparation, Y.-H.L. and M.-L.K.; writingreview and editing, Y.-H.L.; visualization, S.-Y.H.; supervision, M.-L.K. and Y.-H.L.; project administration, M.-L.K. and Y.-H.L.; funding acquisition, M.-L.K. All authors have read and agreed to the published version of the manuscript.

Funding: This research was funded by Soonchunhyang University.

Institutional Review Board Statement: The study was conducted according to the guidelines of the Declaration of Helsinki, and approved by the Institutional Review Board of Soonchunhayng University as such the approval was waived for minimal risk study with no significant human subject experiments.

Informed Consent Statement: Informed consent was obtained from all subjects involved in the study.

Data Availability Statement: All relevant data are within the manuscript. 
Acknowledgments: This research was supported by the Research Institute for Sport Convergence (RISC) at Mississippi State University.

Conflicts of Interest: The authors declare no conflict of interest.

\section{References}

1. George, L.K.; Clipp, E.C. Subjective components of ageing well. Gener. J. Am. Soc. Ageing 1991, 15, 57-60.

2. Crowther, M.R.; Parker, M.W.; Achenbaum, W.A.; Larimore, W.L.; Koenig, H.G. Rowe and Kahn's model of successful ageing revisited: Positive spirituality-The forgotten factor. Gerontologist 2002, 42, 613-620. [CrossRef] [PubMed]

3. OECD. Poverty Rate (Indicator). 2021. Available online: https:/ / data.oecd.org/inequality/poverty-rate.htm (accessed on 30 March 2021).

4. Jacobs-Lawson, J.M.; Hershey, D.A.; Neukam, K.A. Gender differences in factors that influence time spent planning for retirement. J. Women Ageing 2004, 16, 55-69. [CrossRef] [PubMed]

5. Kornadt, A.E.; Rothermund, K. Preparation for old age in different life domains: Dimensions and age differences. Int. J. Behav. Dev. 2014, 38, 228-238. [CrossRef]

6. Kornadt, A.E.; Voss, P.; Rothermund, K. Subjective remaining lifetime and concreteness of the future as differential predictors of preparation for age-related changes. Eur. J. Ageing 2018, 15, 67-76. [CrossRef]

7. Kornadt, A.E.; Voss, P.; Fung, H.H.; Hess, T.M.; Rothermund, K. Preparation for old age: The role of cultural context and future perceptions. J. Gerontol. B Psychol. Sci. Soc. Sci. 2019, 74, 609-619. [CrossRef] [PubMed]

8. Löckenhoff, C.E. Understanding retirement: The promise of life-span developmental frameworks. Eur. J. Ageing 2012, 9, $227-231$. [CrossRef] [PubMed]

9. Muratore, A.M.; Earl, J.K. Improving retirement outcomes: The role of resources, pre-retirement planning and transition characteristics. Ageing Soc. 2015, 35, 2100. [CrossRef]

10. Petkoska, J.; Earl, J.K. Understanding the influence of demographic and psychological variables on retirement planning. Psychol. Ageing 2009, 24, 245. [CrossRef] [PubMed]

11. Park, J.; Fung, H.H.; Rothermund, K.; Hess, T.M. The impact of perceived control and future-self views on preparing for the old age: Moderating influences of age, culture, and context. J. Gerontol. B Psychol. Sci. Soc. Sci. 2020, 75, e18-e28. [CrossRef]

12. Atchley, R.C. Retirement and leisure participation: Continuity or crisis? Gerontologist 1971, 11, 13-17. [CrossRef] [PubMed]

13. Atchley, R.C. A continuity theory of normal ageing. Gerontologist 1989, 29, 183-190. [CrossRef]

14. Staudinger, U.M.; Marsiske, M.; Baltes, P.B. Resilience and reserve capacity in later adulthood: Potentials and limits of development across the life span. Dev. Psychopathol. 1995, 2, 801-847.

15. Freund, A.M.; Riediger, M. What I have and what I do: The role of resource loss and gain throughout life. Appl. Psychol. 2001, 50, 370-380.

16. Black, D.A.; Wilson, L.A.; O'Loughlin, K.; Noone, J.; Kendig, H.; Butcher, J. Housing type, location of residence and health status in Australian baby boomers: Results from the Australian Baby Boomer (ABBA) Study. Australas. J Ageing 2015, 34, 43-46. [CrossRef]

17. Yeung, D.Y.; Zhou, X. Planning for retirement: Longitudinal effect on retirement resources and post-retirement well-being. Front. Psychol. 2017, 8, 1300. [CrossRef]

18. Adams, G.A.; Rau, B.L. Putting off tomorrow to do what you want today: Planning for retirement. Am. Psychol. 2011, 66, 180-192. [CrossRef] [PubMed]

19. Noone, J.H.; Stephens, C.; Alpass, F.M. Preretirement planning and well-being in later life: A prospective study. Res. Ageing 2009, 31, 295-317. [CrossRef]

20. Pinquart, M.; Sörensen, S. Psychological outcomes of preparation for future care needs. J. Appl. Gerontol. 2002, 21, 452-470. [CrossRef]

21. Topa, G.; Moriano, J.A.; Depolo, M.; Alcover, C.M.; Morales, J.F. Antecedents and consequences of retirement planning and decision-making: A meta-analysis and model. J. Vocat. Behav. 2009, 75, 38-55. [CrossRef]

22. Hershey, D.A.; Brown, C.E.; Jacobs-Lawson, J.M.; Jackson, J. Retirees' perceptions of important retirement planning decisions. Southwest J. Ageing 2001, 16, 91-100.

23. Ferrans, C.E.; Powers, M.J. Psychometric assessment of the Quality of Life Index. Res. Nurs. Health 1992, 15, 29-38. [CrossRef] [PubMed]

24. Lawton, M.P. A Multidimensional view of Quality of Life in frail elders. In The Concept and Measurement of Quality of Life in the Frail Elderly; Birren, J.E., Lubben, J.E., Rowe, J.C., Deutchman, D.E., Eds.; Academic Press: Washington, DC, USA, 1991; pp. 3-27. [CrossRef]

25. Lee, S.S. A Study on the Satisfaction of the Korean Elderly according to Their Preparation for Old Ages. J. Consum. Cult. 2012, 15, $43-61$.

26. Kim, D.B.; Jung, G.H.; Lee, E.J. A Study on the Influence of the Previous Preparation for Successful Ageing Life of Elderly and the Mediating Effects of the Life Satisfaction. J. Welf. Aged 2012, 58, 325-352.

27. Hong, S.Y.; Kim, M.L. Scale Development for Universal Retirement Preparation. J. Leis. Stud. 2020, 18, 35-51.

28. Bentler, P.M. Comparative fit indexes in structural models. Psychol. Bull. 1990, 107, 238. [CrossRef] 
29. Hu, L.T.; Bentler, P.M. Cutoff criteria for fit indexes in covariance structure analysis: Conventional criteria versus new alternatives. Struct. Equ. Modeling 1999, 6, 1-55. [CrossRef]

30. Fischer, J.; Corcoran, K.J. Measures for Clinical Practice: Couples, Families, and Children; Free Press: New York, NY, USA, 1994; Volume 1.

31. Silhavy, R.; Silhavy, P.; Prokopova, Z. Analysis and selection of a regression model for the use case points method using a stepwise approach. J. Syst. Softw. 2017, 125, 1-14. [CrossRef]

32. Agahi, N.; Ahacic, K.; Parker, M.G. Continuity of leisure participation from middle age to old age. J. Gerontol. B Psychol. Sci. Soc. Sci. 2006, 61, S340-S346. [CrossRef]

33. Caldwell, L.L. Leisure and health: Why is leisure therapeutic? Br. J. Guid. Counc. 2005, 33, 7-26. [CrossRef]

34. Earl, J.K.; Archibald, H. Retirement planning and resources. Eur. J. Manag. 2014, 14, 21-36. [CrossRef]

35. Noone, J.; O'Loughlin, K.; Kendig, H. Australian baby boomers retiring 'early': Understanding the benefits of retirement preparation for involuntary and voluntary retirees. J. Ageing Stud. 2013, 27, 207-217. [CrossRef] [PubMed]

36. Ryan, R.M.; Deci, E.L. Self-regulation and the problem of human autonomy: Does psychology need choice, self-determination, and will? J. Pers. 2006, 74, 1557-1586. [CrossRef] [PubMed]

37. Rowe, J.W.; Kahn, R.L. Successful ageing. Gerontologist 1997, 37, 433-440. [CrossRef]

38. Earl, J.K.; Bednall, T.C.; Muratore, A.M. A matter of time: Why some people plan for retirement and others do not. Work Ageing Retire 2015, 1, 181-189. [CrossRef]

39. Griffin, B.; Hesketh, B.; Loh, V. The influence of subjective life expectancy on retirement transition and planning: A longitudinal study. J. Vocat. Behav. 2012, 81, 129-137. [CrossRef]

40. Hershey, D.A.; Mowen, J.C. Psychological determinants of financial preparedness for retirement. Gerontologist 2000, 40, 687-697. [CrossRef]

41. Ju, Y.J.; Kim, W.; Lee, S.A.; Lee, J.E.; Yoon, H.; Park, E.C. Lack of retirement preparation is associated with increased depressive symptoms in the elderly: Findings from the Korean Retirement and Income Panel Study. J. Korean Med. Sci. 2017, $32,1516$. [CrossRef]

42. Kim, H.; Prouty, A.M.; Smith, D.B.; Ko, M.J.; Wetchler, J.L.; Oh, J.E. Differentiation and healthy family functioning of Koreans in South Korea, South Koreans in the United States, and white Americans. J. Marital Fam. Ther. 2015, 41, 72-85. [CrossRef]

43. Kim, I.K.; Kim, C.S. Patterns of family support and the quality of life of the elderly. Soc. Indic. Res. 2003, 62, 437-454. 